\title{
Genitourinary Reconstructive Surgery Curriculum and Postgraduate Training Program Development in the Caribbean
}

\author{
Jessica DeLong, $₫$ Ramón Virasoro \\ Department of Urology, Eastern Virginia Medical School, Norfolk, United States, Devine-Jordan Center for Reconstructive Surgery and Pelvic Health, Department of \\ Urology, Virginia Beach, United States
}

\section{Abstract}

Objectives To describe the development of a genitourinary reconstructive fellowship curriculum and the establishment of the first genitourinary reconstructive and pelvic floor postgraduate training program in the Caribbean.

Methods In an effort to respond to the need for specialty-trained reconstructive urologists in the Dominican Republic, we developed an18-month fellowship program to train local surgeons. The process began with creation of a curriculum and partnership with in-country physicians, societies, hospitals, and government officials. We sought accreditation via a well-established local university, and fellowship candidates were selected. A database was maintained to track outcomes. Subjective and objective reviews were performed of the fellows.

Results The first fellow graduated in 2018, the second in 2020, and the third is currently in training. The curriculum was created and implemented. The fellowship has been successfully integrated into the health system, and the fellows performed 199 and 235 cases, respectively, during the program, completing all rotations successfully. They have been appointed to the national health system. Both graduates are now docents in the program and in the public system. Additional staff including radiologists, radiology technicians, nurses, urology residents (both Dominican and American), urology attendings, operating room staff, and anesthesia residents were trained as a result of the program.

Conclusions To our knowledge, this is the first fellowship of its kind in the Caribbean. A novel curriculum was created and implemented, and the first 2 fellows have successfully completed all rotations. This training model may be transferable to additional sites.

\section{Introduction}

Global health and global surgery have gained significant interest and momentum over the last decade[1,2]. Many surgical programs across the United States have implemented a global surgery rotation that highlights the growing interest of American surgical residents in this arena[2-7]. The global health community is committed to furthering surgical care and improving outcomes to reduce health inequities[8]; the Lancet Commission on Global Surgery and other reports have helped to spur this movement $[9-11]$.

\section{Key Words}

Global surgery, reconstructive surgery, curriculum development, surgical training, surgical education

\section{Competing Interests}

None declared

\section{Article Information}

Received on November 13, 2020

Accepted on January 15, 2021

Soc Int Urol J. 2021;2(2):106-112

DOI: https://10.48083/RORD8326 
Over 5 billion people lack access to adequate surgical and anesthesia care across the globe, the majority in low- and middle-income countries (LMICs) [12-14]. This inequity is far-reaching and it has been shown that a significant percentage of the global disease burden is due to surgical conditions: the World Health Organization (WHO) reports $11 \%$, and some contemporary estimates are as high as $30 \%[11-13,15,16]$. This uptrend of surgical burden will likely continue as the world continues to industrialize. Rose and colleagues estimated nearly 34 million urologic procedures were needed in 2010, based on the WHO global health estimate of disease by category[10]. Cogent, compelling arguments have been made by many authors showing how surgical care is an integral part of global health, forming a necessary cog in the network that establishes a strong health system[17]. The need for access to reliable anesthesia and surgery is ubiquitous across countries in all stages of development, as well as across a spectrum of disease states[14].

There are multiple barriers to sustainable surgical programming abroad. Finances, time constraints, and local leadership are all often cited $[1,4,6]$. In order to overcome these obstacles, regional and international investment is important. A local champion should be identified, and any proposed program needs to be able to adapt to the regional environment. The majority of published literature revolves around surgical rotations and fellowships that are based in United States programs, providing short-term rotations in a sustainable environment abroad[1,12,18]. Multi-institutional and multinational co-operations lead to valuable learning experiences and benefits for all participants[4,5] Although some of these advantages may be intangibles such as broadening cultural experience, satisfying altruistic desires or learning about different health care systems, many are concrete. These may include adapting surgical technique, participating in publishing research, and building surgical capacity.

We present our innovative model for surgical education in a resource-poor setting to address a specific need identified by the local community.

\section{Materials and Methods}

In 2013, the authors began weeklong mission trips to the Dominican Republic (DR) in conjunction with Physicians for Peace, a United States-based non-profit organization. Each year a minimum of 2 trips were taken to treat adult men with urethral stricture disease, the prevalence and severity of which are high in the DR. Over this time the Dominican urologists recognized a compelling need for fellowship-trained reconstructive surgeons, and the idea for a formal program was born.

A basic needs assessment was performed during these mission trips and appropriate centralized hospital facilities were identified. A pre-established checklist or survey was not used, but consensus was developed among key stakeholders within the hospitals and residency programs. Essential infrastructure required to support fellowship-level surgical training was identified, including ability to sterilize surgical equipment, availability of basic instruments, and radiology services, as well as anesthesia equipment.

The authors set up a partnership among the following entities: a non-profit organization in the United States (Physicians for Peace), a local prestigious university (Universidad Autónoma de Santo Domingo), and a medical school in the United States (Eastern Virginia Medical School) by the authors. A memorandum of understanding was signed by all parties, and the strengths of each of these organizations, along with other local and international partners, were brought together to form the fellowship.

The first fellow was selected via a longitudinal evaluation spanning 2 years of biannual mission trips, and multiple candidates were considered throughout the country. Subsequent fellows were selected via a nationwide selection process with interviews with the authors. The program is designed for recently graduated urology attendings in the DR who show both an interest in and an aptitude for reconstructive urology. He or she must be fluent in English and in Spanish, able and willing to travel, and motivated to help engender positive change in surgical education.

The curriculum was designed by the authors around established norms for reconstructive urology (Supplemental Material, Curricular Plan, available online), although no formal curriculum yet exists within our international society, Genitourinary Reconstructive Surgeons. The fellowship has been an on-the-ground pilot test for the curriculum and has gone through several iterations since its inception. As there was no existing curriculum within Genitourinary Reconstructive Surgeons, the authors wrote the curriculum based on their expertise in the field as well as with curriculum development. The Ministerio de Educación Superior (MESCyT), the highest office of education in the DR, established standards that were followed within the plan for the fellowship. Via a cooperation between MESCyT and UASD, the current version of the curriculum and overall fellowship plan was incorporated.

The fellow works within the national health system Sistema Nacional de Salud, as well as within the private system. Funding for the first fellow was provided through local and international organizations, as well as through the fellow's billing for services within the private sector. For subsequent fellows, the authors secured a salary through the Ministry of Health. 
A REDCap database was created and maintained to track surgical and perioperative data. The fellows were evaluated during their training and input their cases into a $\log$.

\section{Results}

The needs assessment revealed that there were no fellowship-trained reconstructive urologic surgeons, but a high burden of care due to pathology that could be treated by such a provider. At the major partner hospital, Hospital Moscoso Puello in Santo Domingo, facilities were adequate to perform the required surgeries, although some basic urologic equipment was lacking. Via partnerships and publicity generated from the inception of the fellowship, several key equipment items were donated, including a flexible cystoscope and stirrups for patient positioning. Over the fellowship period, key advances in anesthesia care have also been made.

The curriculum was developed to meet the specific criteria requested by local partners at the Dominican Urological Society and UASD and was designed around 4 major areas. It is to our knowledge the first formally developed curriculum for a fellowship in reconstructive urologic surgery (Table 1). It is meant to be a learning resource, adaptable to the needs of each fellow as well as the needs of the area.

The fellowship is accredited by the UASD, and the fellow graduates with a Diplomate in Reconstructive Urology after 18 months of training. The first fellow graduated in July 2018, and the second in February 2020, and the third was onboarded in March 2020.

The fellows were evaluated subjectively and objectively during each segment of training in the following categories: patient care, surgical skill, and research/academic achievement. Both graduated fellows received "highly satisfactory" or "satisfactory" ratings when evaluated by faculty.

The first graduate performed 199 reconstructive urologic operations, the second 235. These included male urethral reconstruction, procedures related to incontinence and sexual health, and genital reconstruction, as well as female and general urology cases (Table 2). Both fellows rotated externally through Eastern Virginia Medical School as well as centers of excellence in Chile and Argentina for a total of 6 months. The fellow was able to participate in surgical care, conferences and patient care. Regular trips were taken by the authors and other collaborators to the DR to aid in training and consistent telemedicine classes were undertaken to facilitate didactic learning. At a minimum, biweekly conferences were held every 2 weeks.
Surgical and perioperative data, as well as complication rates and follow-up are being collected via an institutional REDCap database. The first graduated fellow logged 18 urethroplasties in his first postgraduate year, and 56 the following year. Additional data regarding etiology, case type, and follow-up were also recorded (Table 3).

\section{Discussion}

To our knowledge, this is the first published genitourinary reconstructive surgery fellowship curriculum and is the first formal genitourinary reconstructive training program in the Caribbean. The success of this program is predicated upon the interest and enthusiasm of our local partners in the DR. These local champions help to support the program on a daily basis. As cited in their work, Riviello and colleagues point to key components of a successful program: relationships, mutual learning, local advocates, local needs superseding those of the visiting institution, research, and a multidisciplinary approach[19]. The authors also recognize these pillars and others, cultivating the relationships with the urological societies and residencies, appreciating the value of education and training, and maintaining openness to collaboration.

This degree program provides the fellow with previously nonexistent resources: access to a network of international surgeons, opportunities to publish and present both nationally and internationally, and a support network to continue program building. It allows for appropriate training and education while providing longitudinal follow-up for patients, facets that have been identified as important to provision of surgical care[20]. The lack of specialty care is reflective of the overall surgical health of the country; it is a privilege to be able to develop a fellowship program when the need for basic surgical care is still unmet in many areas.

There are multiple examples of long-term relationships between academic medical centers and programs in LMICs[19,20] wherein partnerships have been forged to try to address this need. Universities such as Vanderbilt and Harvard have successfully created sustainable training for not only surgeons but also anesthesia providers and nursing staff. Sustainable development, capacity building, and programming are needed, particularly in resource-poor settings, in order to provide long-term solutions[20,21].

The initial needs assessment is very important as this will determine suitability of the site for a specialty training program and define care gaps; several tools have been developed to assess surgical need [22,23]. Surgeons OverSeas developed ways to document baseline surgical capacity in LMICs. Among them is a survey intended 


\section{TABLE 1.}

Fellowship Modules

\section{a) Diagnostic evaluation}

Module 1

- History and physical specific to the specialty

\section{Module 3}

- Urologic endoscopy, urodynamic studies: techniques and interpretation of studies

Module 2

- Radiography, computed tomography, MRI, ultrasound, Doppler:

techniques and interpretation of studies

\section{b) Decision making}

\section{Module 4}

- Relevant anatomy review, review of operative equipment for genitourinary reconstructive surgery

\section{Module 5}

- Interactive case reviews with discussion UASD sponsored course in bioethics (required for master's degree)

\section{c) Surgical techniques}

\section{Module 7}

- Anterior urethral reconstruction: trauma, iatrogenic and inflammatory

\section{Module 8}

- Posterior urethral reconstruction

- Congenital (posterior urethral valves)

- Acquired (trauma, iatrogenic)

\section{Module 6}

- Morbidity and mortality, case presentations
Module 9

- Penile and external genitalia reconstruction

- Correction of congenital and acquired curvature

- Correction of buried penis, genital lymphedema and hidradenitis suppurativa

- Correction of sequelae due to Fournier gangrene and burns

\section{Module 11}

- Male sexual dysfunction

- Penile revascularization

- Penile prosthesis implantation

\section{Module 12}

- Pelvic floor disorders

- Pelvic organ prolapse

- Urinary fistula

- Urethral erosion in patients with neurogenic bladder

\section{Module 10}

- Urinary incontinence in the male and the female

- Injection of suburethral bulking agents

- Autologous and synthetic slings

- Artificial urinary sphincter

- Bladder neck closure, perineal approach and abdominal approach

\section{Module 13}

- Utilization of intestinal segments

- Augmentation cystoplasty

- Continent urinary diversion

- Incontinent urinary diversion

- Ureteral reconstruction

\section{Module 14}

- Hypospadias

- Tubularization of the urethral plate

- Reconstruction with flaps

- Reconstruction with grafts

- Management of chordee to detect care gaps. Divided into sections for Personnel, Infrastructure, Procedures, Equipment, and Supplies, it has been used to provide an index showing surgical capacity. The program in the DR grew from many years of ongoing surgical missions and a formal assessment using one of these established tools was not performed; this is a shortcoming of our work.
The central public Hospital Moscoso Puello is able to serve as a support hub and referral center for surrounding catchment area in the DR, a concept suggested by the WHO global surgery consortium 2030[14]. Building specialty capacity here helps surrounding facilities as well. We continue to meet challenges in some areas where certain equipment remains unavailable. 
TABLE 2.

Fellowship cases

\begin{tabular}{l|c|c|}
\hline & Fellow 1 & Fellow 2 \\
\hline Case type & $\mathbf{n}$ & $\mathbf{n}$ \\
\hline Urethral reconstruction & 96 & 126 \\
\hline Male incontinence & 5 & 5 \\
\hline Male sexual health & 8 & 13 \\
\hline Genital reconstruction & 4 & 2 \\
\hline $\begin{array}{l}\text { Urinary diversion or } \\
\text { ureteral reconstruction }\end{array}$ & 2 & 10 \\
\hline Female reconstruction & 23 & 16 \\
\hline General & 61 & 63 \\
\hline Total cases & 199 & 235 \\
\hline
\end{tabular}

Our collaborative model minimizes cultural and linguistic misunderstandings that can create gaps in care. It allows for an interchange of information that all involved parties find valuable and helps to build a successful system of surgical care. This systemsbased approach requires large-scale efforts from administrators, local champions, and government/ ministry of health representatives, as well as financial engagement. As stated by Paul Farmer and Jim Kim, "To do surgery properly requires a significant investment in infrastructure and training as well as a steady supply of consumables"[24]. Surgery is not simple, nor easy, and it does not bear immediate fruits as a vaccination campaign might.

Many different approaches exist for monitoring and evaluation of these programs. First there is evaluation within the program-competencies for the fellow, presentations given, papers published. We employed a basic, reproducible evaluation form that was completed by faculty involved in training the fellows. Equally important is the impact regionally: patients treated, staff trained, complication rates, and infrastructure change. Various authors have set up schema to measure both need and impact, some with the idea of the creation of national registries to help track surgical encounters in LMICs[10].

Continued program evaluation and outputs analysis both internally with the fellowship as well as externally need to be completed. This program is in its infancy, so long-term data are not available. There is a need to continue to develop programming, as well as to finetune outputs. A REDCap database is maintained to track patient outcomes. Although there have been challenges in culling these data, we can report that the first graduated fellow completed a total of 74 urethroplasties in his first 2 years post training. Data were not available for 17 patients $(22.3 \%)$, but it is of note that a large number of patients developed stricture following placement of urethral catheter for other indications (28, $37.8 \%)$. Interestingly 14 of these patients (18.9\%) had failed prior interventions, consistent with the known prior poor success rates. Follow-up was poorly recorded, and is a shortcoming in our work thus far.

This program is part of a cooperative movement to promote surgical care as an integral part of global health. There are disparities in surgical care, largely based on finances available in the region: Weiser and colleagues reported in 2008 that $30 \%$ of the world's population receives $73.6 \%$ of the surgical care, with the poorest third undergoing only $3 \%$ to $5 \%$ of all surgical procedures[16]. Conditions that require surgical

TABLE 3.

Initial outcomes data: Fellow 1

\begin{tabular}{l|c|c} 
& n & \% \\
\hline Urethroplasties Performed & (74) & \\
\hline Postgraduate year 1 (2018) & 18 & - \\
\hline Postgraduate year 2 (2019) & 56 & - \\
\hline Stricture Etiology & & \\
\hline Foley trauma & 28 & 37.8 \\
\hline latrogenic & 10 & 13.5 \\
\hline Trauma & 7 & 9.5 \\
\hline Lichen sclerosus & 2 & 2.7 \\
\hline Infection & 1 & 1.4 \\
\hline Idiopathic/data not available & 17 & 22.3 \\
\hline Failed prior surgical intervention & $14^{*}$ & $18.9 *$ \\
\hline Surgery Performed & & \\
\hline Excision, primary anastomosis & 18 & 24.3 \\
\hline Oral mucosa graft & 28 & 37.8 \\
\hline Perineal urethrostomy & 5 & 6.8 \\
\hline DVIU/dilation & 3 & 4.1 \\
\hline Data not available & 20 & 27 \\
\hline Results & & \\
\hline Doing well at 2 years (Qmax $>20)$ & 12 & 16.2 \\
\hline Postoperative infection, resolved & 2 & 77 \\
\hline Wound dehiscence, resolved & 1 & \\
\hline Stricture recurrence & 2.7 \\
\hline No data available & & \\
\hline
\end{tabular}

${ }^{*} 5$ of these also had known initial etiology and are listed separately, does not add to 100 
intervention or remediation account for up to $15 \%$ of total disability adjusted life years[24]. While these data highlight the poor access to any procedure, specialty care is also severely lacking.

This study has many limitations. Data collection is incomplete and lacks certain outcome metrics. Much of the impact is challenging to measure in the short term, such as public health initiatives, and is an active area of interest for the authors. As Saluja and colleagues underline, research in academic global surgery needs to have rigorous standards[25]. We are working to improve our understanding of the local and regional impact of this program. Future work will focus on the surgical outcomes, complications, and regional impact of the program. This intent of this study was to describe the fellowship itself.

We met with many challenges in the execution of this fellowship. The curriculum and overall fellowship plan have undergone many iterations. During the first fellow's training, it was challenging to implement and maintain a schedule for didactic lectures. The process was more streamlined with the second and third fellows, and all requirements have now been satisfied. Bureaucracy within the institutions of higher learning led to frequent delays. There have also been many successes: the curriculum was approved, and the fellows were appointed to the national health system (securing a position within the public sector). After the graduation of the first fellow, UASD took over patronage of the fellowship. This is perhaps the greatest sign of sustainability: that the local institution has now assumed the main role as sponsor.

The goal of this fellowship is to improve urologic specialty care in the Dominican Republic. As the fellowship continues to mature, we hope to standardize urologic training in country, show sustainability, and strive for accreditation via the Accreditation Council of Graduate Medical Education. Future plans include expanding the program to other regional applicants as we form a center of excellence.

\section{Conclusions}

A comprehensive genitourinary reconstructive surgery curriculum was developed and accredited by the prestigious New World University. Concomitantly, the first formal training program in genitourinary reconstructive surgery and pelvic floor in the Caribbean was established. Success can be achieved only when there is partnership with local colleagues, and there is much work yet to be done.

\section{Acknowledgments}

The authors would like to thank Physicians for Peace for their support, and Dr Charles Horton, Jr, for providing this opportunity. The guidance and mentorship of Dr Anulfo Lopez was invaluable. They would like to thank Dr Merycarla Pichardo for her support and sponsorship of the program in the Dominican Republic. They would like to particularly thank the docents of the program in Chile and Argentina, Dr Reynaldo Gomez, Dr Leandro Capiel, and Dr Carlos Giudice for their dedication and teaching within the program. They owe a debt of gratitude to Ms Carmen Baxley, surgical technician, for her unparalleled commitment to help those in need. This program would not have been possible without the support and care provided by Dr Ezequiel Ferrara, anesthesiologist.

\section{Author contributions}

Dr Virasoro and Dr DeLong contributed equally to this work in program creation, management, and manuscript preparation. 


\section{References}

1. Zhang LP, Silverberg D, Divino CM, Marin M. Building a sustainable global surgery program in an academic department of surgery. Ann Glob Health. 2016;82(4):630-633.

2. Chao TE, Riesel JN, Anderson GA, Mullen JT, Doyle J, Briggs SM, et al. Building a global surgery initiative through evaluation, collaboration and training: the Massachusetts General Hospital experience. J Surg Educ. 2015;72(4):e21-e28.

3. Knudson MM, Tarpley MJ, Numann PJ. Global surgery opportunities for U.S. surgical residents: an interim report. J Surg Educ.2015;72:e60-65.

4. Cheung M, Healy JM, Hall MR, Ozgediz D. Assessing interest and barriers for resident and faculty involvement in global surgery. $J$ Surg Educ. 2018;75(1):49-57. Epub ahead of print 2017. http:// dx.doi.org/10.1016/j.jsurg.2017.06.031

5. Hugar LA, McCullough CM, Quinn ME, Kapadia SM, Pettitt BJ. Scaling up short-term humanitarian surgery: a global surgery elective for senior medical students. J Surg Educ. 2014;71(6):871-876.

6. Love TP, Martin BM, Tubasiime R, Srinivasan J, Pollock JD, Delman KA. Emory global surgery program: learning to serve the underserved well. J Surg Educ. 2015;72(4):e46-e51.

7. Graf J, Cook M, Schecter S, Deveney K, Hofmann P, Grey D, et al. Coalition for global clinical surgical education: the alliance for global clinical training. J Surg Educ. 2018;75(3):688-696. doi: org/10.1016/j.jsurg.2017.08.019.

8. Dare AJ, Grimes CE, Gillies R, Greenberg SM, Hagander L, Meara JG, et al. Global surgery: defining an emerging global health field. Lancet. 2014;384:2245-2247.

9. Gawande A. The art of medicine: global surgery. Lancet. 2015;386:523-525.

10. Rose J, Weiser TG, Hider P, Wilson L, Gruen RL, Bickler SW. Estimated need for surgery worldwide based on prevalence of diseases: a modelling strategy for the WHO global health estimate. Lancet. 2015; 3(S2):513-520.

11. Ozgediz D, Jamison D, Cherian M, McQueen K. The burden of surgical conditions and access to surgical care in low- and middleincome countries. Bull World Health Organ. 2008;86(8):646-647.

12. Taro T, Yao C, Ly S, Wipfli H, Magee K, Vanderburg R, et al. The global surgery partnership: an innovative partnership for education, research and service. Acad Med. 2016;9175-78.

13. Meara JG and Greenberg SL. The Lancet commission on global surgery global surgery 2030: evidence and solutions for achieving health, welfare and economic development. Surgery. 2015;157(5);834-835.
14. Meara JG, Leather AJM, Hagander L, Alkire BC, Alonso N, Ameh EA, et al. Global surgery 2030: evidence and solutions for achieving health, welfare, and economic development. Lancet. 2015;386:569-624.

15. Frisella MM. Building a sustainable global surgery nonprofit organization at an academic institution. Ann Glob Health. 2016;82(4):649-651.

16. Weiser TG, Regenbogen SE, Thompson KD, Haynes AB, Lipsitz $S R$, Berry WR,Gawande AA. An estimation of the global volume of surgery: a modeling strategy based on available data. Lancet. 2008;372:139-44. DOI:10.1016/S0140-6736(08)60878-8

17. The PLoS Medicine Editors: A crucial role for surgery in reaching the UN millennium development goals. PLoS Med. 2008;5(8):e182. Doi:10.1371/journal.pmed.0050182.

18. Yao CA, Taro TB, Wipfli HL, Ly S, Gillenwater JT, Costa $M A$, et al. The Tsao fellowship in global health: a model for international fellowships in a surgery residency. J Craniofac Surg. 2016;27(2):282-285.

19. Riviello R, Ozgediz D, Hsia RY, Azzie G, Newton M, Tarpley J. Role of collaborative academic partnerships in surgical training, education, and provision. World J Surg. 2010; 34:459-465.

20. Aarabi S, Smithers C, Louis Fils MM, Godson JL, Pierre JH, Mukherjee J, et al. Global surgery fellowship: a model for surgical care and education in resource-poor countries. J Pediatr Surg. 2015; 50:1772-1775.

21. Roa L, Jumbam DT, Makasa E, Meara JG. Global surgery and the sustainable development goals. Br J Surg. 2019;106(2):e44-e52. doi:10.1002/bjs.11044

22. 22. Kushner, Adam L. Operation Health: Surgical Care in the Developing World. Johns Hopkins University Press, 2015.

23. Blair KJ, Paladino L, Shaw PL, Shapiro MB, Nwomeh BC, Swaroop M. Surgical and trauma care in low- and middle-income countries: a review of capacity assessments. J Surg Research. 2017; 210:139-151.

24. Farmer PE, Kim JY. Surgery and global health: a view from beyond the OR. World J Surg. 2008; 32(4):533-536.

25. Saluja S, Nwomeh B, Finlayson SRG, Holterman AL, Jawa $R S$, Jayarman $S$, et al. Guide to research in academic global surgery: a statement of the society of university surgeons global academic surgery committee. Surgery. 2017; doi.org/10.1016/j. surg.2017.10.013. 